\title{
八门七著原告報會究研事短堂天順
}

（）＂縱恰溃舌

舌有梅玉瘍公症

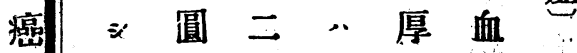

二 殊 形個 舌 未

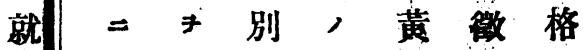

其十種左色 $九$ 中

上 $=$, 㑡;

方 縱 潰 緣 苔

八徑裙 $=$ ”

舌 三相 於 以

, 仙 合 $\bar{F}$

水迷 其 被

本手厅尖八

面橫一端 2

$\exists$ 徑

y 三 + 距

屹 仙 $v n=$

然迷 而

突 $>$ 四腔

隆。，五外

七 $\div$ 仙 $=$

刀其 如 迷 出

后前, ,

部方 即部

，度 $=0$

潰 其始

影卡前 $\boldsymbol{T}=$

一下 部, 其

不部 = 其作

本一位形用

圆埕文不充

形廊口正分

$\Rightarrow$ 樣 $=1$

+ 邊, $\Rightarrow$

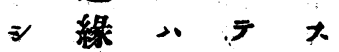

結

a

粘
線之 $\neq 小$

三單點

複反 -

峴 觉 視 明

ス $テ$ 視

可輻 可 ス

₹敕 $\neq$ 的

モ 機。 モ 1

第 不。, 能

$\equiv$ 全。 $=$

圆 $7=\forall$

板 $n=n$

，飞决可

小其 $\approx$

點 適 テモ

分視之雨

一力 眼

々 = 错?

之異視方

）常 大向

明 $t w=$

覣キモ異

（， 常

得, $=$ +

$r=p \neq$

丰於 $三$ 牛

I $=7$

睑 井

膜 褔

唇太

膜 郎

茉

完! 第 严

, 真

娸

真

直
第 
○公認云其痛患モ稍疆疼口起 = 著

○院メ>他又側明鈍道痛內

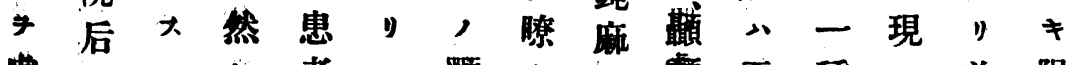

皯, ᄂ者

シ經底

及恖体輕

三一寗 度

厂 三栐，

口月搏 消

七 七

> 目

ト 入

篮

酸

加 稀

里 籃

水 酸

* -

與 $0^{\circ}$

几 機

厂 那

含 丁

制 幾

* 二

命 0

沙 單

可 舍

及 利

的 別

患 四

部 0

及 清

七 水

口-

两 0
等 化

- 障

差 害

$\approx P$

$\rightarrow 1$

(

異 腰

常 背

† 部

,

䛻 鈍

鼠 痛

器

呼 訴

䔩 -

器 又

神 時

經 々

系 誙

等 度

赫，

敢 㥶

于寒

病 7

變》

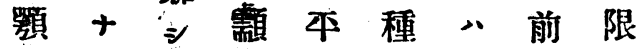

下 $三$ 攵部常, 二部界

腺 ゙苦等多留嗍，

及殊; 二劣奥名潰,

七二蓮堪之中二海

二語艘

三尾自難レッ色比前

》八在キ龙而乾 ス部

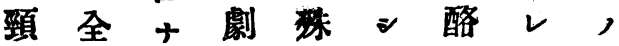

腺》乡痛二テ樣入モ

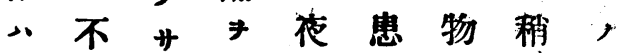

少明的間部

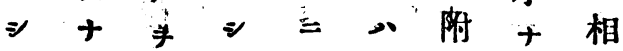

》”以第甚一着》熷

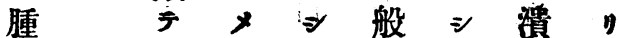

大阻 $=\eta=$ 且激其

七曒安胜”面后

儿㷛眠作起常么万

モ予三，硕心其。

, 霌得兮結少上舌

、 サ 息

如调儿部之》䒕,

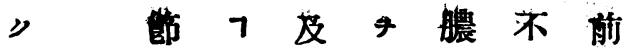

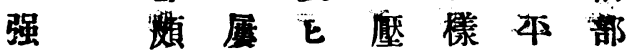

》 放在万粘 $=$ 凡

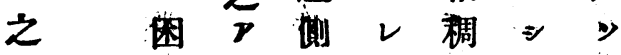

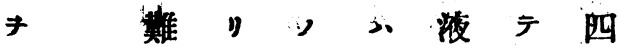

壁二十尔疼 *賴五

大 $シ$ 云䫫痛漏稙仙

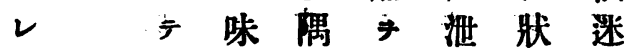

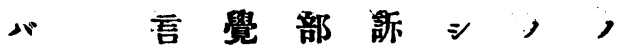

疼部入外〉テ隆部
(O) 苦 率 $=$ 解 ₹ 


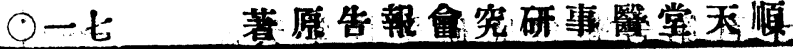

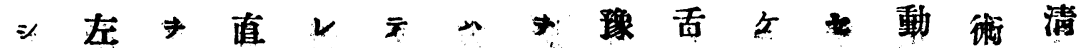

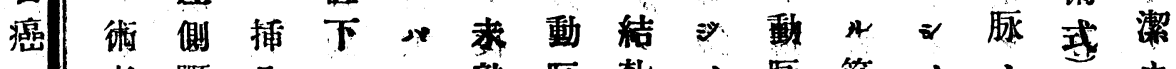

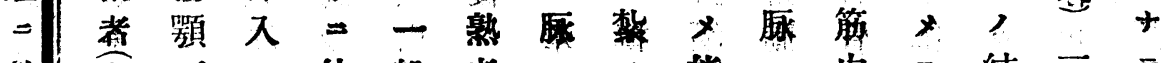

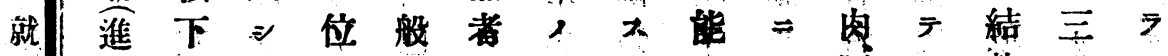

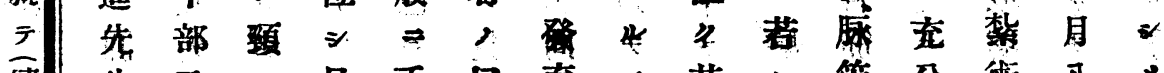

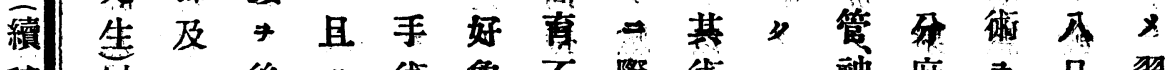

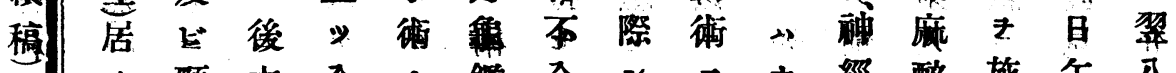

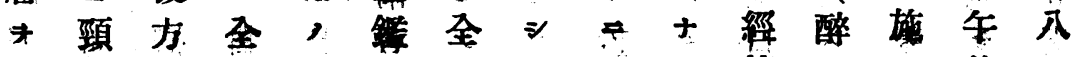

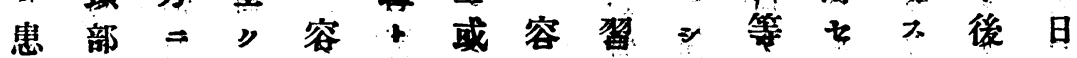

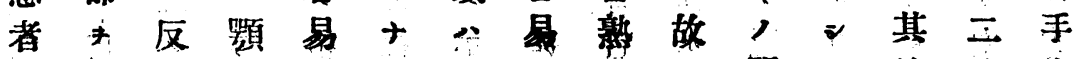

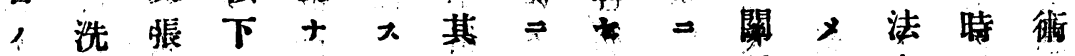

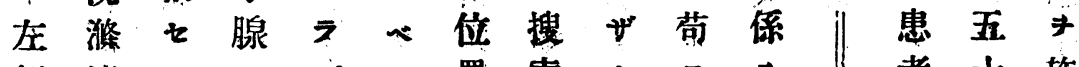

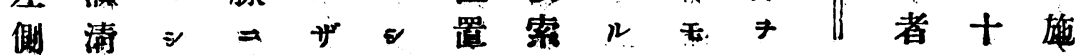

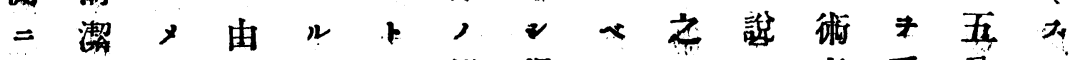

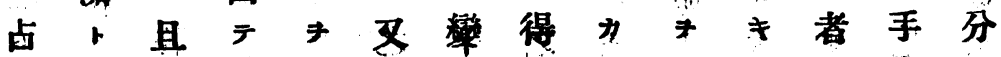

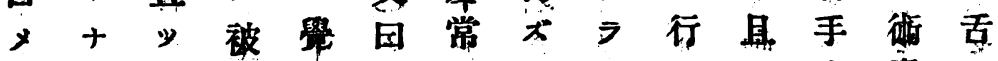

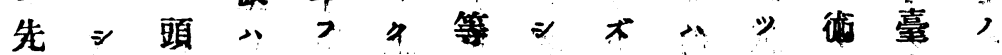
ッ更，

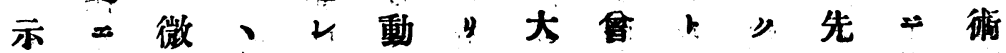
指五 $=$ 者脂拄

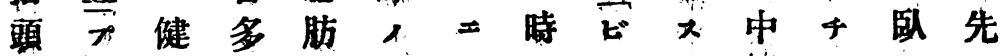

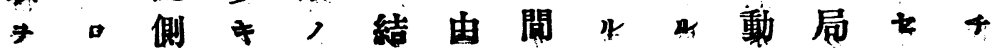

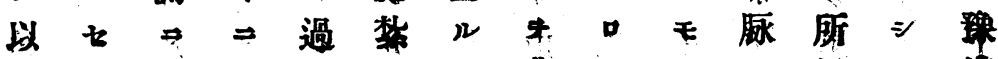

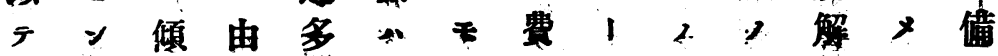

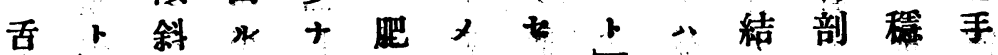

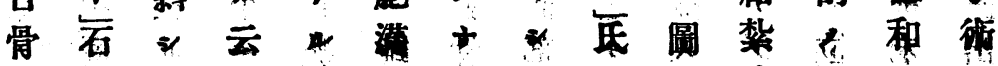

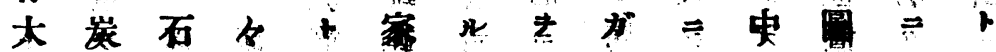

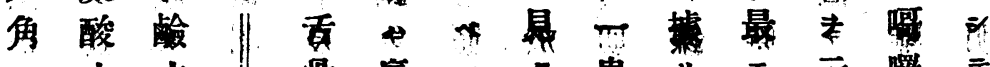

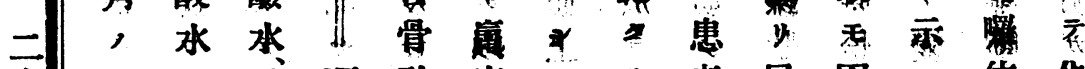

十位

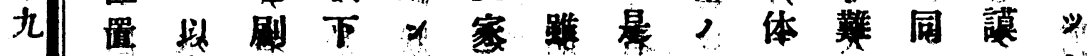

$\neq \bar{*} \neq \neq+\neq$ 质

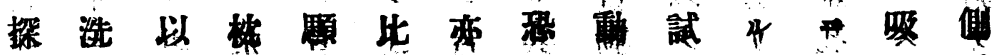

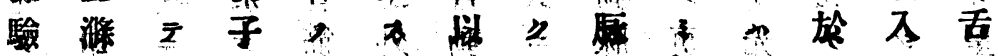


七5正線 $\Rightarrow$, 有永方

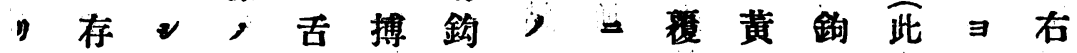

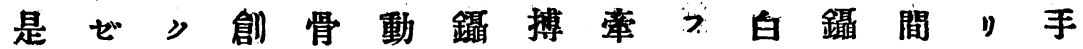
$\Rightarrow n$ 玻内㝒 $*$ 乎動引色子介左 $\Rightarrow$

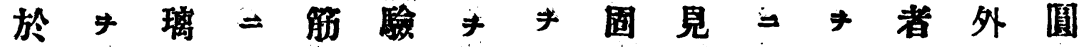

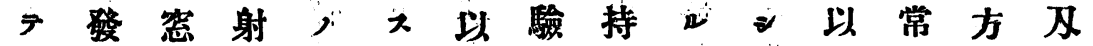

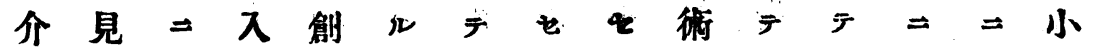

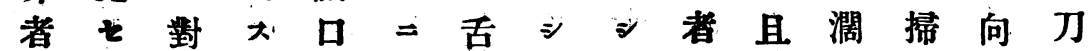
二リ七ル 消由 急 テ メ充大頗觔》指頭肥, 㕛虔》

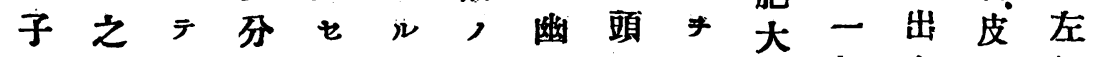

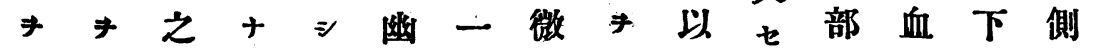

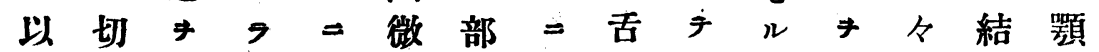
テ 驗ザ舌ナキ之市之顎撮管締下 之ををル動り撮

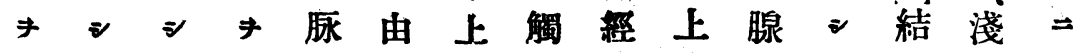
挺 $=$ 以 以 起動舌テ搏有圓 $\approx$ 稍 $=$ 口同 不頸テ

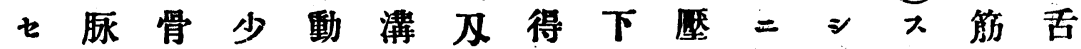

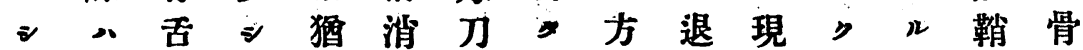
丈 其 筋 $》$ 乐息

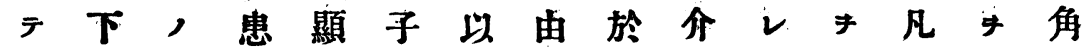

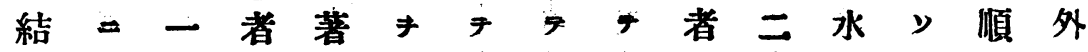
禁露部, ナ挿之該舌 $\Rightarrow$ 腹本三次端

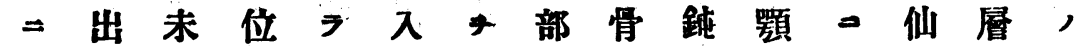

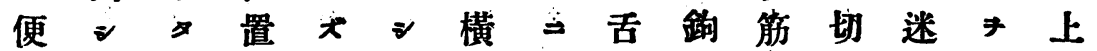
二明離 $\neq$ 時鐮切拎笳 $\Rightarrow$ 及開次逐部

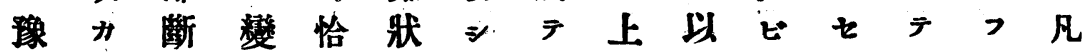

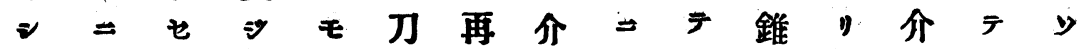
メ搏 $\Rightarrow$ 天 天者貼之狀是者水四

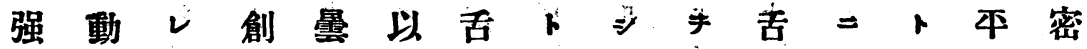

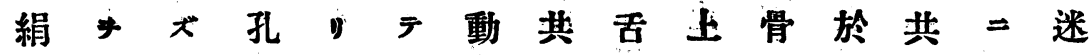

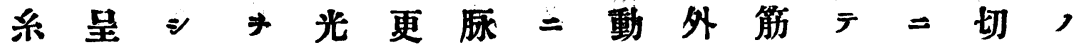




\section{二一七著原告報會究研事醫: 堂天順}

(0)

舌 患舌刀方部口水; 醒》斯》未送

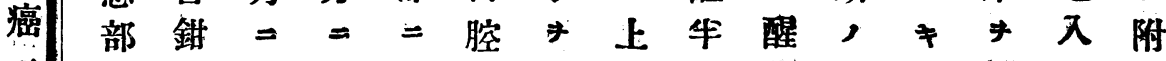

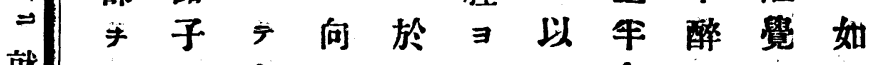

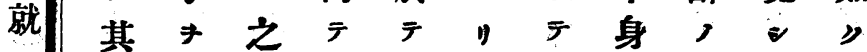

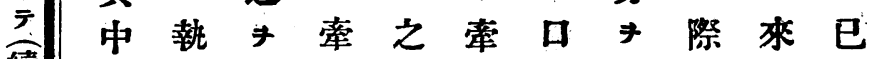
續 央り切引 $三 \neq$ 腔撞 $=n=$ 稿迄患離七穿出殊起於 ま舌

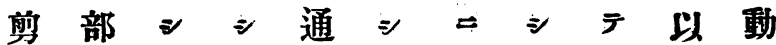
切 $\neq$ 以 $4=$ 大患開 $\approx=$ 尿

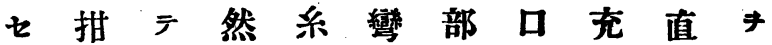
撮舌 ル 端針 二且 $\Rightarrow=\neq=丁 \Rightarrow \Rightarrow=$ 紮

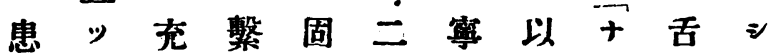
部率分帶 結 條 = テル, テ

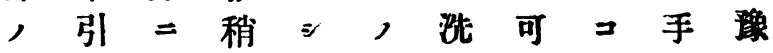

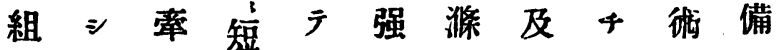
織右引小係絹 $シ$ 的 $カ *$ 手 甚手七二蹄系充口㐌術 $\Rightarrow=* \approx \neq \neq$ 分腔用七全 脆彎メ 》兽術充り 率刀者分以舌法大

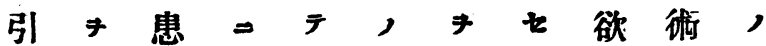
二塟者素介中施 堪り, 引者央 ス だ 日彁 几 前右 $、=、$ 五卜》囉

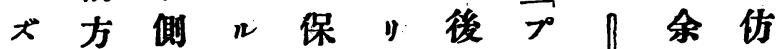

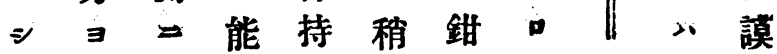

三テり立小它右子七其舌了

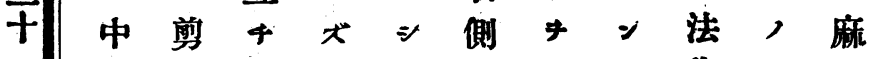
断 左由 せっ手亏舌偏う石义術モ リ己二直７舌炭患》亦 由 = 把剪右 由酸者牛漸

$\approx=$ 布以 $\geqslant F$ ル テ舌 動 創 動 尿 緣 浗 瘤 * * 針 縫 固 合, 其 シ 結 上 沃禁方 度 仿 リ 4 謨 介 二 格 者 腹 鲁 防 顎 查 腐 筋 謨 藥 腱 F液 塗 舌 搳 以 動 七 5 脉 り 創

時 內 間 正 $\%$ 当 $=$ 洗 三涤后 時 $\approx$ 下 四沃方 十度二 命传向 + 謨 テ 


\section{號一十百第告報會究研事醫堂天順 三一七}

么 時 時 服梮 少, 者手

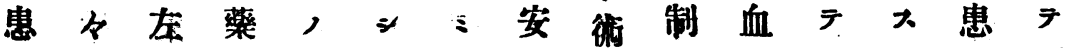
者口项含液甠午靜後、々切ル部更 少丙湖出後 $=$; 管除 $=* \Rightarrow$

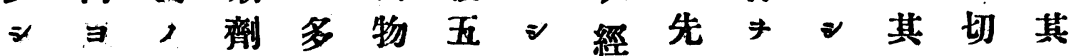
》口創共量俥時テ過 $\neq$ 見以上除后

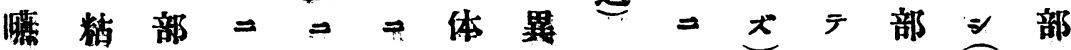
下 $\Rightarrow$ 前甠赤温常捬手是全二介介 因, 疼 = 出色三十后術二”尚者拑 難 液 痛同大末十》⿻上於患木掃撮 , ま $三$ 然帶七唯静ルテ部一血

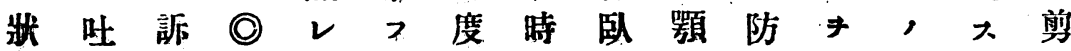

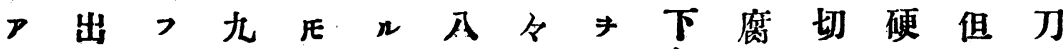

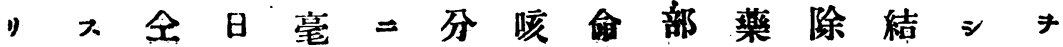

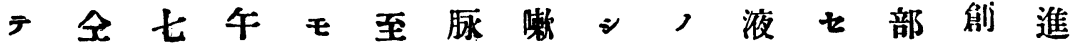

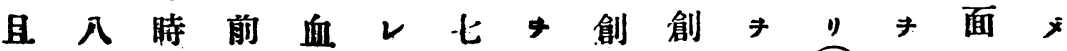
》崚体五液り十發面上以此存

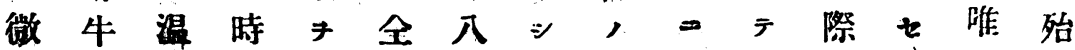
二乳三尿混七至血出入創少》肉 咽五十利七時呼液血法面》由質卜 頭勺七一 $九$ 患吸 二度回暫 者二混制如洗右有血根 疼舆公茶時睡十又七”涤側鈎》，

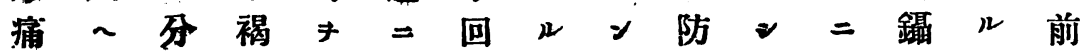
₹少辰色經就全帶力腐水切子, 部 嶨量七 $七$,

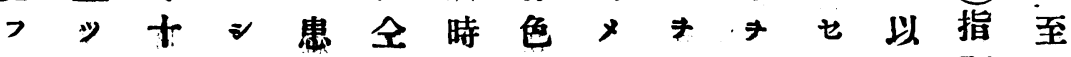
、、至 $テ$ 者十創入冰施含 云徐呼其安一面唾水 $=$ 千 撮 $\Rightarrow$

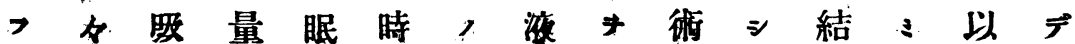

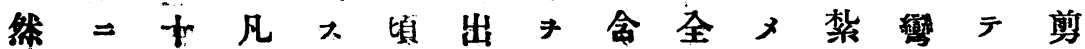

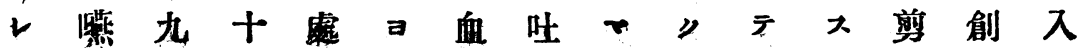
代回污应り大出之了出心刃面

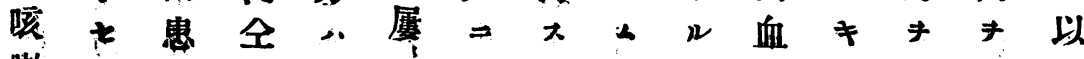
濑 若六内粘减心患 


\section{四一七}

録驗惯告報會究研事醫堂天㮌

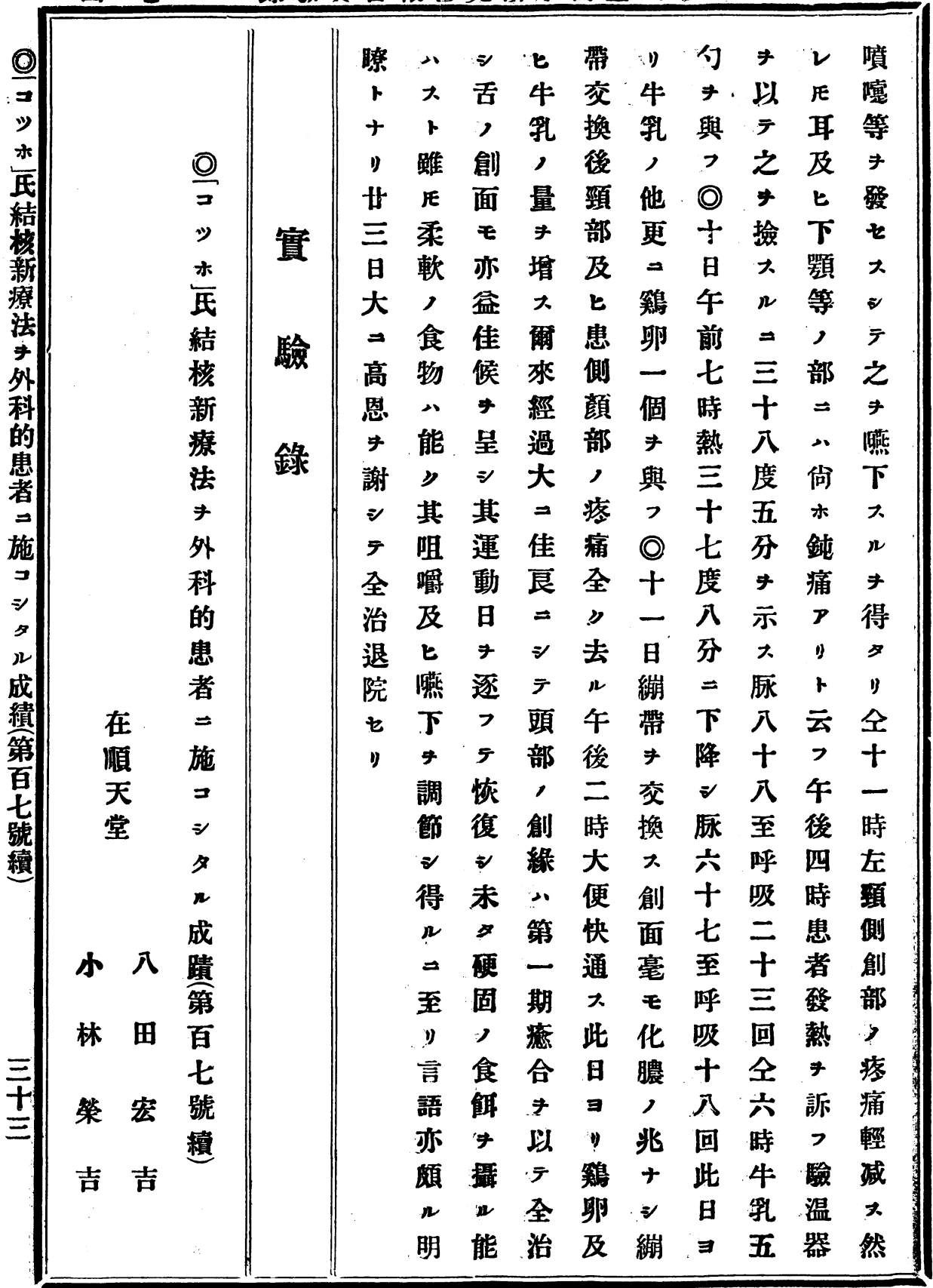

